\title{
FORMAÇÃO DOCENTE UNIVERSITÁRIA E AS POSSIBILIDADES DA INSERÇÃO DA EDUCAÇÃO POPULAR
}

\author{
CHARLINE BEATRICE RITTER BEREGULA \\ Mestranda em Educação pelo Programa de Pós-Graduação em Educação pela URI - Universidade Regional Integrada \\ do Alto Uruguai e das Missões Campus de Frederico Westphalen. Formação em Enfermagem pela URI - FW \\ Pesquisadora da FAPERGS. E-mail: charliritter@ outlook.com \\ LUCI MARI DUSO PACHECO \\ Doutora em Educação. Professora do Programa de Pós-Graduação em Educação URI - Universidade Regional \\ Integrada do Alto Uruguai e das Missões. Câmpus de Frederico Westphalen. End. Profissional: Av. Assis Brasil, 709, \\ Bairro Itapagé, Frederico Westphalen RS. E-mail: luci@uri.edu.br
}

\section{RESUMO}

Este estudo se caracteriza como bibliográfico, e tem como foco os caminhos da docência universitária na área da saúde e as possibilidades de se alcançar um ensino superior de qualidade. A complexidade do processo de ensino/aprendizagem e os fatores envolvidos nas relações entre os sujeitos envolvidos neste processo são elementos discutidos na perspectiva da educação popular. $\mathrm{O}$ desenvolvimento das habilidades do professor, seja ele da área da saúde ou não, perpassa pelo comprometimento profissional e pela corresponsabilização com todos os envolvidos no processo para uma educação de qualidade, para tanto a construção compartilhada dos saberes é o elemento chave para a concretização destas premissas, tendo a educação popular como balizadora. Assim uma formação profissional dentro dos preceitos da educação popular influencia de maneira mais intensa as práticas humanizadoras em saúde, pois a educação popular permeia todos os processos de trabalho dos profissionais de saúde, uma vez que leva em consideração a realidade na qual os sujeitos estão inseridos sua cultura e o modo de vida para estabelecer os modos de cuidado.

Palavras chave: Docência universitária, Área da saúde, Educação popular, Comprometimento profissional.

\section{HIGHER SCHOOL TEACHING EDUCATION AND THE POSSIBILITIES OF ITS INCLUSION IN POPULAR EDUCATION}

\begin{abstract}
This study is characterized as literature, and focuses on the ways of university teaching in health and chances of achieving a higher quality education. The complexity of the teaching/learning and the factors involved in the relationship between the subjects involved in this process are discussed in the perspective elements of popular education. The development of teacher skills, be it healthcare or not, moves through professional involvement and the co-responsibility with everyone involved in the process to a quality education, for both the shared construction of knowledge is a key element in the realization of these assumptions, and popular education as buoy. Thus, a professional formation within the precepts of popular education influences in a more intense way the humanizing practices in health, since the popular education permeates all the work processes of the health professionals, since it takes into account the reality in which the subjects are inserted Their culture and way of life to establish the modes of care.
\end{abstract}

Keywords: University teaching, professional area of health, popular education, commitment.

\section{INTRODUÇÃO}

Uma crescente necessidade de conhecer mais e melhor os professores e seu trabalho docente é a principal intenção do presente estudo, descobrir os caminhos mais efetivos para alcançar um ensino superior de qualidade, igualmente. Pode-se encontrar na fala de Imbérnon (2012) concepções sobre formação que mostram algumas possibilidades para a docência universitária, que procura 
reconhecer o caráter profissional do professorado e a existência de um espaço onde este possa ser exercido, o que implica reconhecer que os professores são verdadeiros agentes sociais, planejadores e gestores do ensino-aprendizagem, não se abreviando ao técnico, mas abarcando a sua capacidade e competência de ajudar na transformação social, a qual é função primordial da universidade.

É sabido que a grande maioria dos professores universitários não teve a formação pedagógica para a atividade docente que exercem, que não ocorreu uma reflexão sobre os aspectos sociais, psicológicos e pedagógicos do seu trabalho, situação na qual acabam por reproduzir os conhecimento da forma como os receberam. Nota-se ainda que, na atual conjuntura das universidades, é imperativo que os professores sejam dotados de ferramentas psicopedagógicas e sociais e não apenas profissionais, isso significa não apenas aprender a ensinar, mas desaprender aspectos que não funcionam no ensino. A conscientização da importância da didática combinada com outros aspectos e o desligamento do empirismo da experiência subjetiva da rotina da sala de aula. (IMBÉRNON, 2012).

Aprender a ouvir, a ter empatia, a respeitar os conhecimentos do outro, sua cultura seus anseios e seus medos, são premissas para desenvolver ações da educação popular dentro da sala de aula ou mesmo fora dela. São ações que podem realmente transformar a realidade do ensino. A formação da profissão docente universitária não ocorre com o desenvolvimento de apenas um fator mas, com uma miscelânea de saberes (científicos, culturais, empíricos) juntamente com algumas características que devem ser trabalhadas de maneira a proporcionar uma aprendizagem ativa dos alunos e gera satisfação a todos os atores do processo.

Esta associação entre as áreas da saúde e da educação também pode ser visualizada suscitando-se as premissas da educação em saúde tão inerentes à profissão de enfermeira e estabelecidas pela Norma Operacional Básica do Sistema Único de Saúde (NOB-SUS 01/96). Vendo assim na educação popular, difundida por Paulo Freire, a interação entre estas. A formação e práticas docentes e a educação em saúde têm significativas contribuições tanto para o ofício docente quanto para os profissionais da área da saúde, e de fato torna-se ainda mais importante a partir do estabelecimento da educação popular em saúde como uma política no âmbito do Sistema Único de Saúde, e a união destas concepções tão conjecturais se concretiza.

\section{PROFISSÃO DOCENTE UNIVERSITÁRIO: ASPECTOS DA FORMAÇÃO}

Marcelo (2009) fala que no processo de desenvolvimento profissional deve-se dar importância às representações, crenças e preconceitos dos docentes, pois afetarão sua aprendizagem da docência e possibilitar ou dificultar mudanças. $\mathrm{O}$ autor destaca ainda a identidade profissional como um elemento inseparável do desenvolvimento profissional e menciona vários fatores que a afetam 
(escola, reformas e contextos políticos), e suas implicações, como o compromisso pessoal, a disponibilidade para aprender a ensinar, os valores, o conhecimento sobre as disciplinas que ensinam e como as ensinam, as experiências passadas, e a própria vulnerabilidade profissional.

O desenvolvimento da profissão docente universitária não pode ser vista de maneira restrita, sendo que não se deve unicamente ao desenvolvimento pedagógico, ou à compreensão de si mesmo, ou ao desenvolvimento cognitivo, ou ainda apenas ao desenvolvimento teórico/científico, mas sim todos esses fatores unidos acrescidos de um contexto que permita o desenvolvimento destas capacidades. Sendo um fator de grande relevância o aprimoramento da formação. (IMBÉRNON, 2012). “A formação deve ser um elemento dinamizador para aprender a questionar o que se vê, aquilo em que se acredita e o que se faz. Ajudar a repensar a prática docente a partir da consciência da contextualização e da complexidade do ato educativo" (IMBÉRNON, 2012, p.115).

Para Pimenta e Anastasiou (2011, p. 105)

A construção da identidade com base numa profissão inicia-se no processo de efetivar a formação na área. Assim, os anos passados na universidade já funcionam como preparação e iniciação ao processo identitário e de profissionalização dos profissionais das diferentes áreas.

Revelar quão mister se faz uma boa formação dentro da universidade é mostrar, igualmente quão bem estruturada se tornará a identidade do profissional seja qual for sua área de atuação. Porém, sabe-se que a identidade do educador, é um fator que foi-se perdendo durante a trajetória da educação e que precisa ser resgatada para que junto com ela regate-se também a sua autonomia e sua valorização enquanto tal.

Em relação a identidade, Pimenta e Anastasiou (2010, p. 77) assinalam que:

A identidade não é um dado imutável. Nem externo, que possa ser adquirido como uma vestimenta. E um processo de construção do sujeito historicamente situado. A profissão do professor, como as outras, emerge em dado contexto e momento histórico, como respostas a necessidades apresentadas pelas sociedades, adquirindo estatuto de legalidade.

Pode-se entender, a partir das palavras das autoras, que a identidade do professor é, também, algo que está em constante movimentação, pois este é um sistema de elaboração, de idealização de situações exigidas do profissional em seu contexto sócio histórico.

Assim, uma identidade profissional se constrói com os significados e reafirmações que os atores, que fazem parte desse meio analisam e realizam, de forma ética, tentando implementar novas e diversas possibilidades que são preciosas para sua prática e sua identidade enquanto professor.

Ainda, de acordo com Pimenta e Anastasiou (2010, p. 77): 
Uma identidade profissional se constrói, pois, com base na significação social da profissão; na revisão constante dos significados sociais da profissão, na revisão das tradições. Mas também com base na reafirmação das práticas consagradas culturalmente que permanecem significativas.

É possível compreender que a identidade do professor provém de seu sentido social dentro da profissão, de uma verificação das tradições, da ação entre a teoria e a prática. Essa identidade se forma, igualmente, a partir da importância que cada profissional dá a sua própria função como professor, levando em conta seus valores éticos e sociais, sua participação na vida comunitária e acadêmica, seus próprios saberes, tanto de experiências quanto de conhecimento, de suas heranças históricas, de suas relações com alunos, colegas, instituições, enfim dele com todas as esferas relacionadas ao ensino.

A identidade do professor constrói-se, do mesmo modo, a partir das exigências que o mesmo vai encontrando em determinadas situações ou contextos os quais vai se deparando no decorrer de seu trabalho, e que lhe vai exigindo, de certa forma, assumir determinadas posturas que lhe orientem durante esse processo.

Libâneo (2004, p.68) apresenta que identidade profissional é:

O conjunto de conhecimentos, habilidades, atitudes e valores que definem e orientam a especificidade do trabalho do professor. Sabemos que a profissão de professor vai assumindo determinadas características - isto é - determinada identidade - conforme necessidades educacionais colocadas em cada momento da história e em cada contexto social.

Pode-se pensar que a identidade do professor, então, depende de fatores que são desenvolvidos durante toda a sua formação docente: habilidades, conhecimentos gerais ou específicos, valores, atitudes, enfim, elementos que formam um bom professor. A identidade está, desta forma, ligada a uma boa formação docente a qual deve ser um processo dinamizador e constante no contexto atual.

Também, na concepção de Imbernón (2012, p. 96-97):

[...] a profissão docente universitária se desenvolve por diversos fatores: sua categoria acadêmica, a cultura das faculdades, as disciplinas, os departamentos, as universidades, o salário, a demanda do mercado em que se trabalha a promoção dentro da profissão, as estruturas hierárquicas, a carreira docente etc., e é claro, pela relação com os colegas, com os alunos e com a formação permanente que essa pessoa vai realizando ao longo de sua vida profissional.

A partir desta perspectiva a identidade do professor se desenvolve e/ou se forma na confluência de vários fatores que acabam por configurar a individualidade de cada professor na profissão do ensino universitário por meio de sua formação docente, sua bagagem de vida, sua trajetória profissional. 
As universidades abarcam alguns profissionais iniciantes na carreira de ser professor os quais nunca tiveram uma formação que englobe conhecimentos pedagógicos; teórico-práticos, que se reconheça sujeito do processo de "formação", do "saber fazer" e de seu aluno integrado a um contexto do qual este faz parte desse processo do "saber", bem como as relações e situações que se travam entre esses atores, contudo, trazem em sua bagagem histórica, a experiência de sua vida acadêmica e pessoal, o que o auxilia a enfrentar a prática do seu cotidiano, evoluindo assim sua identidade enquanto profissional.

Pode inferir pelo que lemos anteriormente que docência no ensino superior necessita que os professores de outras áreas, que não a Licenciatura, procurem especializações como pós-graduações latu-sensu ou stricto-sensu, bem como congressos, fóruns, simpósios, meios que sirvam de apoio para auxiliar na construção de sua identidade enquanto docente.

A formação docente e a construção de sua identidade deve ser entendida como um aprendizado profissional que ocorre ao longo da vida, o que implica envolvimento dos professores em processos intencionais e planejados, que possibilitem mudanças em direção a uma prática efetiva em sala de aula. (ANDRÉ, 2010). Significando que os conhecimentos pertinentes ao profissional professor são perenes, se estendem por toda a existência do indivíduo, sendo um apanhado de características e habilidades desenvolvidas para um melhor exercício profissional.

Lanier (1984, p.30) já suscitava que:

Os professores possuem um amplo corpo de conhecimentos e habilidades especializadas que adquirem durante um prolongado (prolongado se aceitarmos a formação como desenvolvimento durante toda a vida profissional) período de formação.

Segundo o autor o saber dos professores deve ser um saber versátil, plural, polivalente, que contenha saberes de várias fontes, e que sejam adquiridos, da mesma forma, durante sua toda formação, os quais darão origem a novos saberes e novos conhecimentos.

Podemos percebem isso quando Imbernón (2011, p.31) destacou que:

[...] a necessidade de um conhecimento polivalente que compreenda diferentes âmbitos: o sistema (em suas estruturas próprias, sintáticas, ideológicas ou em sua organização), os problemas que dão origem à construção dos conhecimentos, o pedagógico geral, o metodológico-curricular, o contextual e o dos próprios sujeitos da educação.

As palavras dos autores salientam a necessidade de um conhecimento plural, ou seja, um conhecimento o qual abarque um vasto campo de saberes que contribuam para a realização de sua prática, bem como, a reflexão sobre a mesma, e, consequentemente para a aprendizagem como um todo. 
Ao mesmo tempo em que é plural, os saberes são temporais, pois advém de uma história vida, de um caminho trilhado pelos educadores durante sua própria trajetória escolar e de formação. Tardif (2008, p.19-20) nos traz que:

O saber dos professores é plural e também temporal, uma vez que, como foi anteriormente, é adquirido no contexto de uma história de vida e de uma carreira profissional. [...]. Em suma, entes mesmo de começarem a ensinar oficialmente, os professores já sabem, de muitas maneiras, o que é ensino por causa de toda a sua história escolar anterior.

Vários autores comungam da mesma ideia de que alguns saberes são de grande valia, com tal caraterística, para a prática pedagógica dos professores no seu contexto escolar. Tais os saberes são nomeados com sendo os saberes da experiência, os saberes do conhecimento e os pedagógicos. (PIMENTA, 2010; TARDIF, 2008).

Os saberes da experiência são aqueles que carregam em seu cerne as experiências de todo o um percurso de vida, de relações com outros, de uma prática pedagógica e reflexão do professor sobre a mesma.

Nas palavras de Pimenta (2012, p. 22):

Os saberes da experiência são também aqueles que os professores produzem no seu cotidiano docente, num processo permanente de reflexão sobre sua prática, mediatizada pela de outrem - seus colegas de trabalho, os textos produzidos por outros educadores.

Para a autora, os saberes experienciais são aqueles produzidos dentro e fora do ambiente escolar, mas em um caminho continuo, do dia a dia, onde o professor atua em sala de aula para posteriormente refletir sobre a mesma, trocando ideias com colegas, gestores, e porque não com os próprios alunos para tornar sua prática mais e mais eficaz.

Os saberes da experiência possibilitam o professor atuar de forma autônoma, flexível e reflexiva em sala de aula. Ainda, esses saberes não se encontram em teorias, eles são saberes práticos que vão acrescentando mais e mais prática naquilo que o professor desenvolve que o ajuda a atuar de acordo com as situações que se apresentarem a ele durante sua prática.

Tardif (2008, p. 49) ressalta que:

Os saberes experienciais estão enraizados no seguinte fato mais amplo: o ensino se desenvolve num contexto de múltiplas interações que representam condicionantes diversos para a atuação do professor. Esses condicionantes não são problemas abstratos como aqueles encontrados pelo cientista, nem problemas técnicos, como aquele com os quais se deparam os técnicos e os tecnólogos. [...] Com o docente é diferente. No exercício cotidiano de sua função, os condicionantes aparecem relacionados a situações concretas que não são passíveis de definições acabadas e que exigem improvisação e habilidade pessoal, bem como a capacidade de enfrentar situações mais ou menos transitórias e variáveis.

Pode-se depreender das palavras acima citadas que os saberes experienciais possuem, então, sua origem no contexto de atuação dos professores, ou seja, no seu dia-a-dia em sala de aula com 
suas variáveis e que exigem dele uma reflexão e ação momentânea, rápida, que acabam por criar um ambiente de reflexão, atualização e ação nas situações que se criam no seu cotidiano de sala de aula.

Freire (2001) traz a concepção de comprometimento profissional, lembrando que antes de ser profissional, é um homem e, sendo a primeira condição para o homem possa exercer um ato comprometido é a sua capacidade de atuar e refletir. É exatamente esta capacidade de atuar, operar, de transformar a realidade, que está associada sua capacidade de refletir, que o faz um ser da práxis. Envolta, portanto, no compromisso do profissional, seja ele quem for, está a exigência de seu constante aperfeiçoamento, de superação do especialismo, que não é o mesmo que especialidade. $\mathrm{O}$ profissional deve ampliar seus conhecimentos em torno das pessoas, de suas formas de ser e de ver o mundo, substituindo por uma visão crítica a visão ainda ingênua da realidade, deformada pelos especialismos que possibilitam conhecer apenas parte do todo.

A formação será legitima quando contribuir para o desenvolvimento profissional do professorado no âmbito trabalhista e de melhoria das aprendizagens profissionais no contexto em que se trabalha, ajudando desta forma, a melhorar o ensino e a aprendizagem dos alunos o que se constitui como objetivo fundamental da docência universitária. (IMBÉRNON, 2012). Estes conceitos perpassam pelas premissas da valorização profissional assim como o reconhecimento do caráter social da profissão de professor.

Imbérnon (2012) refere que existem fatores decisivos e de grande proeminência no desenvolvimento do processo de ensino e aprendizagem como, por exemplo, a comunicação entre aluno e professor. A comunicação é entendida neste contexto como a possibilidade de dar voz aos alunos, através da qual se demonstra respeito pelas ideias do outro e aceitação das diversidades para a construção de uma convivência harmoniosa e democrática entre as pessoas. Justamente pelo fato de a comunicação não ser linear, ou seja, a comunicação é um processo no qual se transmite informação e entendimento de um indivíduo para o outro, envolvendo interpretação. O professor precisa estar atento ao feedback, modificando sua mensagem constantemente em razão do que observa e escuta de si mesmo e dos alunos. Concordando com a fala de Freire sobre o respeito ao educando:

Estas qualidades ou estas virtudes absolutamente indispensáveis à posta em prática deste outro saber fundamental à experiência educativa - saber que devo respeito à autonomia, à dignidade e à identidade do educando - não são regalos que recebemos por bom comportamento. As qualidades ou virtudes são construídas por nós no esforço que nos impomos para diminuir a distância entre o que dizemos e o que fazemos. (FREIRE, 1996, p.38).

As qualidades indispensáveis citadas por Freire, supracitado, são elementos de caráter ético que levam em consideração as características individuais do aluno: respeito à autonomia, à 
dignidade e à identidade. São habilidades primazes a serem desenvolvidas pelos educadores, podese fazer relação neste momento com a capacidade de escuta pelo professor, aptidão que, quando livre de pré julgamentos pode ser de valor inestimável para o conhecimento dos anseios e o fortalecimentos de uma relação respeitosa com os alunos.

Ouvir ativamente é uma capacidade crítica de influência que engloba diversos comportamentos que comunicam aos alunos e alunas que eles estão sendo ouvidos e compreendidos, que os sentimentos subjacentes a suas palavras são apreciados e aceitos e que, sejam quais forem seus pensamentos ou palavras, cada um deles é aceito como pessoa. A finalidade consiste em comunicar que, independentemente das ideias, acontecimentos, atitudes e valores do estudante que fala, quem escuta não avalia essa pessoa por suas ideias e sentimentos. (IMBÉRNON, 2012, p. 71)

Ouvir atentamente os alunos é uma forma de comunicação de suma importância na aprendizagem, todavia é necessário que esta escuta seja sem julgamentos de ideias, de atitudes ou valores. $\mathrm{O}$ ato de julgar afasta e dificulta a empatia e ouvir requer paciência e que se transmita confiança e respeito. A empatia surge do reconhecimento das semelhanças, e para se reconhecer se faz necessário ouvir sem julgar e procurar encontrar pontos comuns para se fazer um elemento de ligação no relacionamento entre aluno e professor.

Entende-se ausência de julgamento diferentemente de neutralidade, pois esta característica pregada por alguns seria a negação da existência de valores, o que poderia fazer com que todo o processo do ensino e aprendizagem ficasse em um nível muito superficial para realmente transformar, como pode-se observar nesta fala de Freire:

[...] não é falando aos outros, de cima para baixo, sobretudo como se fossemos os portadores da verdade a ser transmitida aos demais, que aprendemos a escutar... somente quem escuta paciente e criticamente o outro, fala com ele. O educador que escuta aprende a difícil lição de transformar o seu discurso, às vezes necessário, ao aluno, em uma fala com ele. (FREIRE, 1996, p. 71).

Na relação com a área da saúde, os termos escuta qualificada e acolhimento são transversais e amplamente conhecidos e utilizados no dia a dia do atendimento aos clientes pelos profissionais de saúde. O acolhimento é um modo de operar os processos de trabalho em saúde de forma a atender a todos que procuram os serviços de saúde, ouvindo seus anseios e assumindo uma postura capaz de acolher, escutar e pactuar respostas adequadas aos usuários. Implica prestar um atendimento com resolutividade e responsabilização. $\mathrm{O}$ conceito de acolhimento se concretiza no cotidiano das práticas de saúde por meio de escuta qualificada Uma postura acolhedora implica em estar atento e poroso à diversidade cultural, racial e étnica. (BRASIL, 2004)

A educação popular em saúde é considerada como uma das estratégias básicas para a promoção da saúde das pessoas. Ela acontece na sociedade, realizada com grupos, coletividades e movimentos sociais. Entende-se que toda prática educativa se realiza entre pessoas, isto é, envolve 
sujeitos portadores de vivências subjetivas e objetivas e que interpretam tais vivências segundo sua cultura e sua inserção social. São, portanto, práticas que têm no diálogo a base fundamental para a interação com o outro, princípio fundamental da prática pedagógica. (BRASIL, 2008).

As concepções de educação popular estão amplamente difundidas em documentos do ministério da saúde para os profissionais de saúde e gestores de forma a ampliar os conhecimentos destes a respeito deste assunto tão intimamente relacionado com as práticas de educação em saúde:

A educação popular é compreendida como perspectiva teórica orientada para a prática educativa e o trabalho social emancipatórios, intencionalmente direcionada à promoção da autonomia das pessoas, à formação da consciência crítica, à cidadania participativa e à superação das desigualdades sociais. A cultura popular é valorizada pelo respeito às iniciativas, ideias, sentimentos e interesses de todas as pessoas, bem como na inclusão de tais elementos como fios condutores do processo de construção do trabalho e da formação. (BRASIL, 2012, p. 5).

Como pode-se observar, estes conceitos são muito bem aceitos pela área da saúde e se encaixam perfeitamente nas práticas educativas humanizadoras desenvolvidas pelos profissionais da saúde. Desde a Declaração de Alma-Ata, URSS (setembro de 1978) - Saúde para Todos no Ano 2000 e a Atenção Primária de Saúde, nesta a participação popular é expressa como uma diretriz pelos países articulados a OMS (Organização Mundial da Saúde). (BRASIL, 2002).

Reafirma-se a participação popular na Carta de Ottawa, Canadá (novembro de 1986), que resultou da I Conferência Internacional sobre Promoção da Saúde (1986); a Declaração de Adelaide, Austrália (abril de 1988) que reafirmava as linhas de ação da Carta de Ottawa; a Declaração de Sundsvall, Suécia (junho de 1991) conclamava sobre a importância do ambiente saudável para a saúde; a Declaração de Santafé de Bogotá, Colômbia (novembro de 1992) tratou da promoção da saúde na América Latina; a Declaração de Jacarta, Indonésia (julho de 1997) teve como tema a promoção da saúde no século XXI. (BRASIL, 2002). Todos estes documentos, e muitos outros, reiteram a participação popular nas práticas em saúde, o respeito às diferenças, à valorização dos indivíduos e de sua cultura.

\section{A EDUCAÇÃo BANCÁRIA}

A educação bancária, segundo Freire (1987), é um modo de repasse de informações, o educador faz comunicados ao invés de comunicar-se, e os educandos são meros receptores de conteúdos pré-estabelecidos. Para Freire, na situação que os educandos se fazem depósitos, não emerge sua consciência crítica, ou seja, é imposto a eles (os alunos) o que devem acreditar e o quanto devem saber, e quando se colocam nesta posição inferior tendem a aceitar passivamente o mundo como ele é, sem perspectiva de mudá-lo: 
Quanto mais se exercitem os educandos no arquivamento dos depósitos que lhe são feitos, tanto menos desenvolverão em si a consciência crítica de que resultaria a sua inserção no mundo, como transformadores dele... Quanto mais se lhes imponha passividade, tanto mais ingenuamente, em lugar de transformar, tendem a adaptar-se ao mundo, à realidade parcializada nos depósitos recebidos. (FREIRE, 1987, p. 34).

Também conhecida como tradicional ou preventiva, é um o modelo ainda muito utilizado por professores em todos os níveis de ensino. A questão é que este subjuga os conhecimentos prévios dos indivíduos, desconsiderando o meio onde vivem estas pessoas, sua cultura, situação onde o senso crítico não está presente, as informações já estão 'prontas', escritas, e é caracterizada como uma forma narrativa e portanto estática indo totalmente contra os princípios de criatividade e da mudança. (FREIRE, 1987).

Para Imbérnon (2012), alguns professores podem se sentir satisfeitos após uma aula meramente transmissora (bancária), isto porque, durante séculos, a universidade caracterizou-se por ter aulas expositivas como metodologia. Entretanto, com as novas atitudes sociais, as inovações tecnológicas e o próprio comportamento dos alunos, iniciou-se um debate sobre os meios utilizados para ensinar e aprender. $\mathrm{Na}$ vida cotidiana ninguém ouve o outro de maneira ininterrupta e toma notas e apenas pergunta quando solicitado, se isso seria irracional na vida cotidiana porque seria usual e lógico na universidade? Para o autor, alguns professores têm a distorção perceptiva de se sentir satisfeitos depois de horas falando, em um monólogo, nas salas de aula, sem se dar conta de que estão contrariando princípios de comunicação elementar.

Relacionando com a Educação em Saúde Alvim e Ferreira (2007) trazem que, diante do impasse de que o paciente, na opção por orientar suas práticas de saúde fundamentadas pelo saber científico, dele fica dependente, ao tomar esse conhecimento como verdade absoluta e definitiva, surge a situação desafiadora para o ato educativo dialógico em saúde: a de transformar a posição ingênua dos sujeitos educandos em posição crítica, diante desse suposto "acabamento" e "conclusividade" do conhecimento científico.

\section{POSSIBLIDADES DA EDUCAÇÃO POPULAR}

Paralelamente à educação bancária está a educação radical, problematizadora ou popular, a qual coloca educador e educandos no mesmo patamar de conhecimentos mas, em áreas diferentes. $\mathrm{Na}$ educação problematizadora a premissa é o diálogo, e esta relação dialógica é indispensável à cognoscibilidade dos sujeitos. (FREIRE, 1987).

A educação popular traz a concepção de igualdade entre os indivíduos, no sentido de que todos nós temos conhecimentos prévios ao momento em que nos deparamos com uma situação de aprendizagem ou de troca, como num grupo de saúde, por exemplo. Durante uma simples exposição de um tema estamos praticando a educação tradicional enquanto, quando nos preocupamos com o 
tema de interesse de nosso público, trazendo referências do cotidiano deles e incentivando a participação de todos (cada um a sua maneira), aí sim estamos praticando a educação popular.

Desta maneira, o educador já não é o que apenas educa, mas o que, enquanto educa, é educado, em diálogo com o educando que, ao ser educado, também educa. Ambos, assim, se tornam sujeitos do processo em que crescem juntos e em que os argumentos de autoridade já não valem. (FREIRE, 1987, p. 39).

Relacionando estes conceitos com o campo da saúde, embora já existam várias iniciativas de natureza ética no sentido de respeitar e valorizar a participação e autonomia do sujeito nas ações relativas ao seu bem-estar, ainda hoje se constata a predominância do modelo de educação linear, de orientação depositária, que se ancora em um modelo escolar de dominação. Nele, se substitui a ideologia da cultura comum pela ideologia da cultura científica. Observando a terminologia no processo pedagógico em saúde, encontramos um direcionamento pautado em verbos operacionais, como "orientar". (OLIVEIRA, 2005).

A maior diferença apontada por Oliveira (2005), entre o modelo bancário e o modelo popular é que esse último busca, muito mais, a mudança social do que a transformação pessoal. Supõe-se que indivíduos conscientes sejam capazes de se responsabilizar pela sua própria saúde, não apenas no sentido da sua capacidade para tomar decisões responsáveis quanto à saúde pessoal, mas, também, em relação à sua competência para articular intervenções no ambiente que resultem na manutenção da sua saúde. O modelo radical em saúde surge em resposta às premissas da Política de Promoção à Saúde.

A educação se refaz constantemente na práxis, não aceita um futuro estático, sem possibilidade de mudanças, a educação se baseia num presente dinâmico, que está em movimento, e tem a intenção de desenvolver pessoas críticas, de si mesmos e do mundo que vivem, transformando-o. (FREIRE, 1987). O pensamento crítico e a análise das ações em todos os momentos do processo de ensino/aprendizagem, seja este na universidade ou em uma unidade de saúde, o respeito às características culturais, físicas, intelectuais, financeiras e psicológicas dos indivíduos envolvidos são as diretrizes para o cumprimento desta concepção de educação.

A utilização deste tipo de educação, a popular, é uma alternativa de grande valia para a o desenvolvimento das ações por professores universitários, assim como por profissionais da área da saúde, pois faz com que o conhecimento seja construído, tendo mais aceitação e interesse dos atores do processo. Esta interação é enriquecedora e gera muito mais satisfação para todos os participantes, devendo ser considerado o fato de que não existe um fim, uma conclusão para um problema, quando se trata de educação popular o empenho é permanente e a transformação contínua. 
A educação popular em saúde implica em fazer com que as informações sobre a saúde dos grupos sociais contribuam para aumentar a visibilidade sobre sua inserção histórica, social e política, a elevar suas reivindicações e projetar caminhos. Ao colocar-se como referência no campo das práticas dos profissionais, a educação popular contribui para a formação de profissionais comprometidos com as questões sociais, engajados ativamente na luta pelos direitos dos usuários e com uma postura mais acolhedora na construção da autonomia das pessoas. (BRASIL, 2007).

Concordando com Freire (2001), ao sentir e viver o comprometimento, em um ato consciente, os homens não são neutros. A neutralidade frente ao mundo reflete apenas o medo que se tem de revelar o compromisso. Ingenuidade seria pensar numa prática abstrata, num conjunto de métodos e técnicas neutras para uma ação que se dá entre homens, entre pessoas humanas, e sobretudo numa realidade que não é neutra.

De acordo com Imbérnon (2012), a formação e a prática deveriam apoiar-se em uma reflexão dos sujeitos sobre sua prática docente, em um troca entre iguais, no desenvolvimento do pensamento reflexivo, examinando suas teorias implícitas, suas atitudes, ou seja, perguntar-se por que fazem o que fazem, realizando um processo contínuo de auto avaliação e análise que possa orientar para a mudança. Refletir sobre o que se faz e para que se faz, transpondo as capacidades e habilidades e indo além na questão dos valores e concepções tácitas de cada professor. "Se faz necessário mudar o que se pensa e se sente para melhorar o que se faz." (IMBÉRNON, 2012. p. 102).

Nesse sentido, observa-se que não é no silêncio que os homens se fazem, mas na palavra, isto implica em que educadores e educandos, que estão inseridos criticamente na história, assumam uma posição de sujeitos que compõem o mundo e não simplesmente reproduzem saberes científicos, concebido como unicamente verdadeiro e definitivo. Muitas vezes são nas próprias vivências, na sua práxis existencial que se extraem demandas de aprendizagem, aprendendo com os próprios desafios. Partindo do pressuposto que o aprendizado tem diferentes dimensões, pode-se tirar daí a essência da prática, e sua realização anseia muito mais que a adaptação ou a acomodação, mas permite a transformação da realidade. (FREIRE, 1987).

\section{DESENVOLVIMENTO DA DOCÊNCIA UNIVERSITÁRIA}

Estudos recentes nos mostram que a docência se desenvolve na grande maioria das vezes na prática, ou seja, os profissionais que ensinam na sala de aula adquirem conhecimento prático somente com o exercício da prática pedagógica. Até mesmo uma licenciatura recebe informações, aprende técnicas e vivencia experiências com os conteúdos curriculares que se remetem à profissão docente e ao trabalho pedagógico, significa que eles têm acesso às sistematizações organizadas, 
manuseia balizamentos teóricos e desenvolve várias competências essenciais à futura profissão de educador. Entretanto, ainda assim não está praticando o ofício docente, na verdade esse aluno está exercendo a prática de estudante e não a de professor. (SILVA, 2009).

Diante de tais pressupostos, Rios (2011) assinala um caminho: resgatar o sentido primeiro de educação como condição para a realização dos indivíduos, pensando na relevância da atuação profissional como intermediário entre o educando e a realidade, a partir de cujo conhecimento ele poderá atuar e transformar, transformando desta maneira a si próprio.

Observa-se aqui a visão do docente universitário como mediador, e não como detentor único do conhecimento e com a responsabilidade solitária de repassá-lo aos alunos. Se o ofício docente se aprimora no dia a dia e se consolida com o tempo, a melhor maneira de encarar a complexidade do processo de ensino e aprendizagem pode ser a da corresponsabilização e o compartilhamento dos saberes. Para Rios (2011) nesta perspectiva, professor e aluno são sujeitos conhecedores, o professor estabelece o diálogo entre o aluno e o real, e não consigo próprio, desta forma o mundo passa a ser apreendido, compreendido e alterado.

A formação deveria dotar o professor de instrumentos intelectuais que sejam úteis ao conhecimento e à interpretação das situações complexas em que se situa e, por outro lado, envolver os professores em tarefas de formação comunitária para dar à educação escolarizada a dimensão de vínculo entre o saber intelectual e a realidade social, com a qual deve manter estreitas relações. (IMBÉRNON, 2011, p.42).

Observa-se desta maneira a relevância da formação do docente, no sentido de dar subsídios para os problemas que se apresentarão na prática. Mesmo compreendendo a prática como, muitas vezes, elemento chave para o desenvolvimento da consciência de ações mais comprometidas e da real compreensão do papel do educador, ainda assim acredita-se que a formação traz os principais balizamentos intelectuais necessários para desenvolver o ofício docente.

Concordando com Rios (2011) as afirmações sobre a atuação do professor aplicam-se também aos profissionais de outras áreas. A consciência das implicações de suas ações nas relações com os sujeitos estimula ações criativas e mais sensíveis às necessidades de todos os envolvidos. $\mathrm{E}$ é exatamente na prática diária que a história é construída, tanto a individual quanto a coletiva. "É a partir dos profissionais que somos que vamos caminhar para os profissionais que queremos ser" (RIOS, 2011, p.109).

Tem-se neste momento a necessidade de identificar as necessidades, mas principalmente de conscientizar-se da importância da mudança. Compreender a formação como um elemento dinamizador, requer uma práxis reflexiva e crítica e, além disso, superar modelos estabelecidos. O professor tem uma função social marcadamente forte e uma função formadora de indivíduos como o foco diário de suas ações. Na fala de Imbérnon pode ser identificado o papel do professor formador: 
O professor/formador deve fornecer a criação dos espaços de reflexão necessários para que os alunos aprendam e sejam protagonistas de seu próprio processo de construção de conhecimentos durante toda a vida. Refletir é aprender a pensar, analisar, comparar, sintetizar e tirar conclusões, a tomar decisões, enfim, o pensamento reflexivo é toda uma série de capacidades. (IMBÉRNON, 2012, p.90).

$\mathrm{Na}$ oportunidade da formação têm-se possibilidade ímpar de conscientizar todos os envolvidos no processo de ensino/aprendizagem, conscientizar de seu espaço, de sua história e principalmente, de sua importância na transformação da realidade que se apresenta. A partir da consciência de ser e estar no mundo, a partir da troca de saberes, da compreensão do docente de seu papel social, pode-se falar em mudança ativa, com o envolvimento de toda a comunidade/sociedade e em função destas.

A formação docente universitária, dificilmente terá caráter obrigatório então, para haver uma mudança, precisa passar pela conscientização dos professores a respeito da necessidade de melhorar a relação com a transmissão da disciplina, consigo mesmo e com os alunos. Seria necessária uma mudança de posicionamento das estruturas organizacionais universitárias, assim como das estruturas cognitivas dos professores, para que haja envolvimento individual e coletivo que ocorra pela reflexão e investigação sobre os efeitos da docência universitária na sociedade. (IMBÉRNON, 2012).

\section{CONCLUSÕES}

A educação popular, da qual deriva a educação popular em saúde, se apresenta como possibilidade humanizadora das práticas profissionais dos professores. A concepção do professor como um mediador entre o aluno e o mundo, assim como a construção compartilhada dos saberes parece ser os elementos chave para a educação que se quer.

O caminho da humanização passa pelo entendimento de que o outro possui necessidades e que somos responsáveis por resolver/amenizar algumas delas, obviamente não será possível resolver todos os problemas dos pacientes que atendemos, mas se for possível com alguns, de maneira a causar uma transformação em sua saúde e sua vida, então todo o trabalho terá valido a pena e o discurso sobre humanização da assistência se torna realidade.

Pode-se afirmar que, se a formação é voltada para as práticas humanizadoras acaba se traduzindo em práticas humanizadas, principalmente com exemplos, modelos profissionais, começando pelos professores, supervisores de estágio e profissionais. Modelos exitosos devem fazer parte da formação do enfermeiro para que se possa ter uma base sólida de como agir no futuro profissional. É essencial que haja muito exercício, diálogo, troca de saberes e de experiências em sala de aula (ou laboratório) antes de partir para a prática, e que nos campos de estágio onde os profissionais estão atuando, possam auxiliar no desenvolvimento das atividades dos alunos, que a 
participação seja real, e que os alunos possam deixar a sua marca, realizar projetos e que estes tenham continuidade com as próximas turmas.

O cuidado comprometido, a ética e a humanização fazem parte da base de sustentação da possibilidade real da mudança, é a ratificação da capacidade das pessoas, seja em qualquer nível de escolaridade que possuam, de poder transformar sua situação de sofrimento em aprendizado e melhora. A falsa superioridade que o modelo positivista propôs para os profissionais da saúde distanciou as pessoas, dificultou as relações entre profissionais de saúde e pacientes, é imperativo superar este modelo e partir para uma perspectiva de equidade, que humaniza as relações.

O futuro almejado está sendo construído no presente que está sendo vivido agora. Para transformar é necessário superar os problemas e idealizar o novo modo de ser professor, seja ele de que área for, respeitando a si mesmo e ao outro. Pode-se observar que muitas dificuldades podem ser apontadas, que inúmeras justificativas podem ser elencadas, mas não se deve perder de vista o comprometimento e a responsabilidade atrelados ao papel do professor em todas as sociedades.

Se por um lado há uma crise que atinge a toda a humanidade, é necessário responder à ela, e que resposta melhor teríamos que uma educação primorosa? Sabe-se que estas utopias, para se tornarem realidades concretas, necessitam de empenho e dedicação, mas sabe-se também que existe uma coletividade em busca de uma educação de qualidade, reitera-se aqui as possibilidades da educação popular para a realização desta.

Vive-se um período de profundas transformações na sociedade como um todo, nas relações de trabalho e pessoais, nos conceitos, nos comportamentos e, talvez seja este o momento de se resgatar o cuidado no seu sentido pleno, pois, é a partir de grandes mudanças na sociedade que as transformações internas acontecem. Convém rever conceitos antigos e formas ultrapassadas de resolver problemas e de desenvolver o trabalho dos profissionais da saúde e se adaptar a esta forma mais fluida de viver, mais leve, mais humana.

\section{REFERÊNCIAS}

ALVIM, Neide Aparecida Titonelli; FERREIRA, Márcia de Assunção. Perspectiva problematizadora da educação popular em saúde e a enfermagem. Texto contexto - enferm. Florianópolis, v. 16, n. 2, 2007.

ANDRÉ, Marli. Formação de professores:a constituição de um campo de estudos. Educação, Porto Alegre, v. 33, n. 3, p. 174-181, set./dez. 2010

BRASIL. Ministério da Saúde. HumanizaSUS: Documento base para gestores e trabalhadores do SUS. Secretaria de Atenção à Saúde, Núcleo Técnico da Política Nacional de Humanização. 4. ed. Brasília: Ministério da Saúde, 2010. 
BRASIL. Secretaria de Gestão Estratégica e Participativa - Departamento de Apoio à Gestão Participativa. Bases para a Educação em Saúde nos Serviços. Ministério da Saúde, Brasília DF,2008.

BRASIL. Ministerio da Saude. Caderno de educacao popular e saúde. Secretaria de Gestao Estrategica e Participativa. Departamento de Apoio à Gestao Participativa. Brasilia: Ministerio da Saude, 2007.

BRASIL. Ministério da Saúde. HumanizaSUS: acolhimento com avaliação e classificação de risco: um paradigma ético-estético no fazer em saúde. Secretaria de Atenção à Saúde. Núcleo Técnico da Política Nacional de Humanização. Brasília: Ministério da Saúde, 2004.

BRASIL, Ministério da Saúde. As Cartas da Promoção da Saúde. Brasília: Ministério da Saúde, 2002.

BRASIL. Lei 9.394, de 20 de dezembro de 1996. Lei de Diretrizes e Bases da Educação Nacional. Brasília, 1996.

COSTA, Áurea de Carvalho; MARAFON, Adriana Maria Mattos. A constituição do professor como trabalhador. HISTEDBR On-line, Campinas, n.36, p. 153-166, 2009.

DAVID, Helena Maria Scherlowski Leal; BONETTI, Osvaldo Peralta; SILVA, Maria Rocineide Ferreira da. A Enfermagem Brasileira e a Democratização da Saúde: notas sobre a Política Nacional de Educação Popular em Saúde. Rev. Bras. Enferm. Brasília, 65(1): 179-85, 2012.

DAVID, Helena Maria Scherlowski Leal; ACIOLI, Sonia. Mudanças na formação e no trabalho de enfermagem: uma perspectiva da educação popular e de saúde. Rev. bras. enferm. Brasília, v. 63, n. 1, 2010.

FISCHER, Beatriz Terezinha Daudt. Docência no Ensino Superior: Questões e Alternativas. Educação. Porto Alegre, n.3, v.32, p.311-315, 2009.

FIGUEIRA, Maura Cristiane e Silva; LEITE, Tânia Maria Coelho; SILVA, Eliete Maria. Educação em Saúde no Trabalho de Enfermeiras em Santarém do Pará, Brasil. Rev. Bras. Enferm. Brasília, 65 (3): 414-9, 2012.

FREIRE, Paulo. Educação e Mudança. 12. ed. Paz e Terra, 2001.

FREIRE, Paulo. Pedagogia da Autonomia: saberes necessários à prática educativa. São Paulo: Paz e Terra, 1996.

FREIRE, Paulo; SHOR, Ira. Medo e Ousadia - O Cotidiano do Professor. Rio de Janeiro: Paz e Terra, 1986.

FREIRE, Paulo. Pedagogia do Oprimido. 17. ed. Rio de Janeiro: Paz e Terra, 1987.

FREIRE, Paulo. Conscientização: teoria e prática da libertação: uma introdução ao pensamento de Paulo Freire. São Paulo: Cortez \& Moraes, 1979. 
GOMES, Alfredo Macedo. MORAES, Karine Nunes de. Educação Superior no Brasil Contemporâneo: Transição para um sistema de massa. Educ. Soc. Campinas, n.118, v.33, p.171190, 2012.

IMBÉRNON, Francisco. Formação docente e profissional: formar-se para a mudança e a incerteza. 9 ed. São Paulo: Cortez, 2011.

IMBÉRNON, Francisco. Inovar o ensino e a aprendizagem na Universidade. São Paulo: Cortez, 2012.

JOAQUIM, Nathália de Fátima; VILAS BOAS, Ana Alice; CARRIERI, Alexandre de Pádua. Entre o Discurso Praticado e a Realidade Percebida no Processo de Formação Docente. Avaliação, Campinas. Sorocaba SP, n.2, v.17, p.503-528, 2012

MACEDO, Elizabeth. Currículo e Conhecimento: Aproximações entre Educação e Ensino. Cadernos de Pesquisa. n. 147, v. 42, p.716-737, 2012.

MARCELO, Carlos. Desenvolvimento Profissional: passado e futuro. Sísifo - Revista das Ciências da Educação, n. 08, p. 7-22, 2009.

MCCULlOCH, Gary. História da Educação e Formação de Professores. Revista Brasileira de Educação. n.49, v.17, 2012.

OLIVEIRA, Dora Lúcia. A 'nova' saúde pública e a promoção da saúde via educação: entre a tradição e a inovação. Rev Latino-am Enfermagem , 13(3):423-31, 2005.

PFEIFER, Mariana. Dicotomias Conceituais da Avaliação da Educação Superior. Avaliação, Campinas. Sorocaba SP, n.2, v.17, p.351-364, 2012.

PIMENTA, Selma. G. Didática e Formação de professores: percursos e perspectivas no Brasil e em Portugal. 6a Ed. São Paulo: Cortez, 2011.

PIMENTA, S. G. ANASTASIOU, L. das G. C. Docência no Ensino Superior - $4^{\mathrm{a} e d .}$ - São Paulo: Cortez, 2010.

TARDIF, Maurice. Saberes Docentes e Formação Profissional. 4. ed. Petrópolis, RJ: Vozes, 2008.

RIOS, Terezinha Azerêdo. Ética e competência. 20. ed. São Paulo: Cortez, 2011.

SANTOS, Gildeon Borges dos. Usos e Limites da Imagem da Docência como Profissão. Revista Brasileira de Educação. n.52, v.18, 2013.

SILVA, Marilda da. Complexidade da Formação de Professores: Saberes Teóricos e Saberes Práticos. São Paulo: Cultura Acadêmica, 2009.

SOUZA, Aparecida Neri de. Fronteiras entre Duas Esferas das Atividades Sociais: A Educação e o Trabalho. Educ. Soc. Campinas, n.118, v.33, p.81-95, 2012. 
Revista do Programa de Pós- Graduação em Educação da UFPI| ISSN 1518-0743

Aceito em: 25.05.2017 